\title{
The Similarities and Differences between Low-carbon Economy, Circular Economy and Their Overall Development
}

\author{
Xin Zhao, Yannan Gao \\ Shandong Women's University, Jinan, China
}

Keywords: low-carbon economy; circular economy; similarities and differences; coordinated development

\begin{abstract}
Circular economy and low-carbon economy are self-reflection for human being facing the crisis of resources, environmental pollution and ecological destruction, and a new understanding and summary for the relationship between man and nature. Only when we grasp the opportunity and actively develop these two economic models can we make China's economic and ecological environment develop in step with each other. Based on the author's study and practical experience, this paper first analyzed the theories about low-carbon economy and circular economy, and then studied the harmonious development trend of low-carbon economy and circular economy, finally put forward the countermeasures of circular development of circular economy and low-carbon economy.
\end{abstract}

\section{Introduction}

Since the reform and opening up, our country has been taking economic construction as the center, advocating efficiency first and giving consideration to fairness. As a result, the national economy has witnessed tremendous development and the people's living standards have been greatly improved. However, all these achievements have paid a great price of resources and environment, and the contradiction between economic development and resource environment is becoming more and more acute. If we do not speed up the restructuring and change the growth pattern, resources will not be able to support, the environment will not be able to accommodate, the society will not be able to afford it, and economic development will be difficult to sustain. Ecological civilization is the result of profound reflection on the traditional form of civilization, which requires the establishment of sustainable mode for the production and consumption. In other words, it is to establish a circular economy and low-carbon economy coordinated development model.

\section{The theories about low-carbon economy and circular economy}

\subsection{Theory related to low-carbon economy}

Low-carbon economy is a science that studies the structure and function of nature, and human beings are also regarded as a component of nature. Ecology is a natural science that studies the law and mechanism of interaction between life system and environment system. In order to analyze the relationship between human beings and environment, British ecologist Stanley put forward the concept of ecosystem. In his opinion, an ecosystem is a whole of a system that includes not only organic complexes, but also the whole physical complex factor that forms the environment. This system is the basic unit of nature on the surface of the earth and it has a variety of sizes and species. Stanley looked at the composition of the ecosystem, which is shown in figure 1.

One of the most basic principles of ecology is the principle of recycling and regeneration, which holds that the structure and functions of natural ecosystems are symmetrical, and it has a complete structure of producers, consumers and decomposers. Self-fulfilling material cycle and energy information flow characterized by production-consumption-decomposition-reproduction. A healthy 
natural ecosystem can realize the good development of the ecological circle through the effective regulation of the system itself. There is a universal symbiotic relationship between the resources, environment, population, society and economy in the cycle and the low-carbon economy, to form a complex ecosystem in which man and nature depend on each other and flourish together. Therefore, from the perspective of sustainable development, the development of circular economy and lowcarbon economy follow the principle of recycling and regeneration of ecosystem, ecological threshold rule, and ecological threshold law. The recycling and regeneration structure of ecological composite system is recoupled to realize the function of resource, environment and social economy coordination and symbiosis, to maintain the stability and efficiency of ecosystem, and to realize the sustainability of system development.

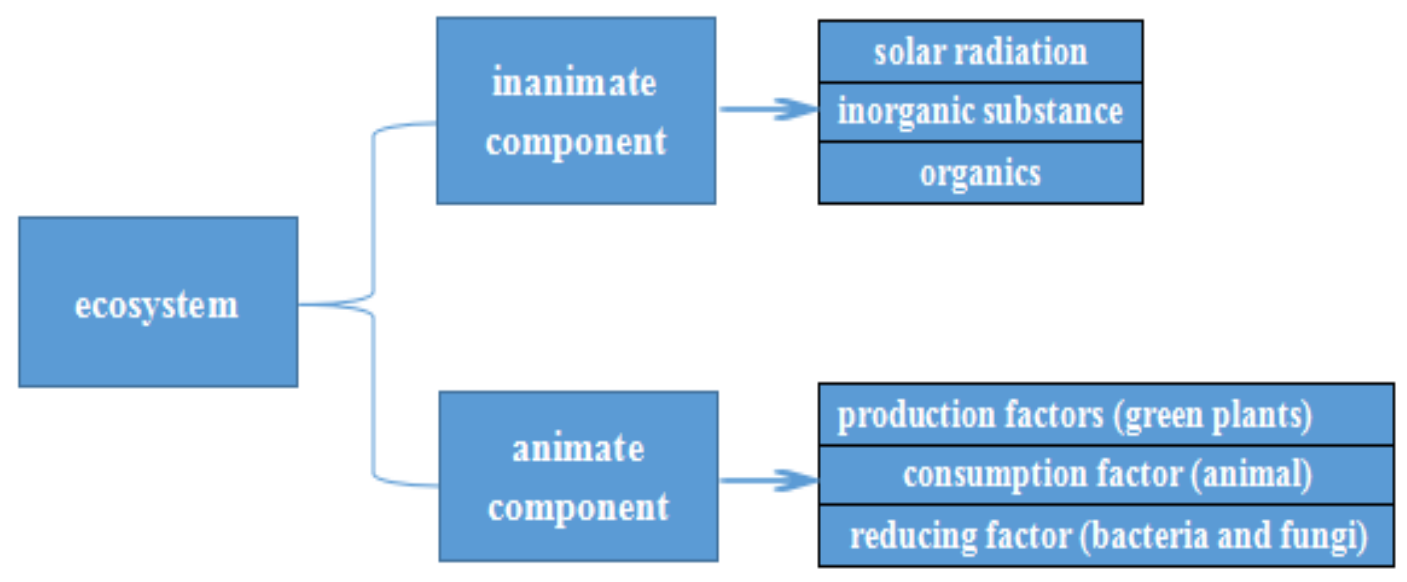

Fig. 1 The composition of the ecosystem

\subsection{Circular economics}

Circular economics was first proposed by Kenneth E. Boulding, an American economist, in the middle of 1960s. The essential feature of circular economics is to save resources and protect the environment to the maximum extent, which is consistent with the objectives of circular economy and low-carbon economy in essence. In 1976, Sakamoto, Japan, became the world's first systematic monograph on ecological economics. More than 50 years have passed, and through the continuous improvement of scholars from various countries, ecological economics has become an important branch of modern economics. The material and energy cycle between economic system and ecosystem, information exchange and value increment are the key research fields.

Ecological economics regards ecosystems and economic systems as a composite system, focusing on the mechanism of interaction between ecological environment and economic activities, in order to provide theoretical guidance for environmental protection, resource management and economic sustainable development. It not only provides theoretical basis for macro strategic choice, but also provides guidance for micro production, management and consumption.

Daly points out that in traditional economics, the economic system is regarded as an isolated system that does not consider the exchange of material and energy around the environment. what's flowing is a value of exchange abstracted from the physical dimensions, nothing comes from and depends on the surrounding environment, and naturally there will be no resource depletion and environmental pollution. Daley criticizes that the shortcomings of traditional economics lie in ignoring the problems of natural resource consumption and environmental pollution, and focusing on the theory of growth. Like natural ecosystems, there are material producers, consumers and decomposers in socio-economic systems. However, the socio-economic system is an open composite system, which has a large amount of material exchange and energy cycle with the outside world. However, the disintegrators of the current socio-economic system are not functioning properly and do not match the functions of producers and consumers, resulting in low utilization of resources. Pollution cannot be eliminated (see figure 2). Therefore, the decomposers are 
restructured to improve their function.

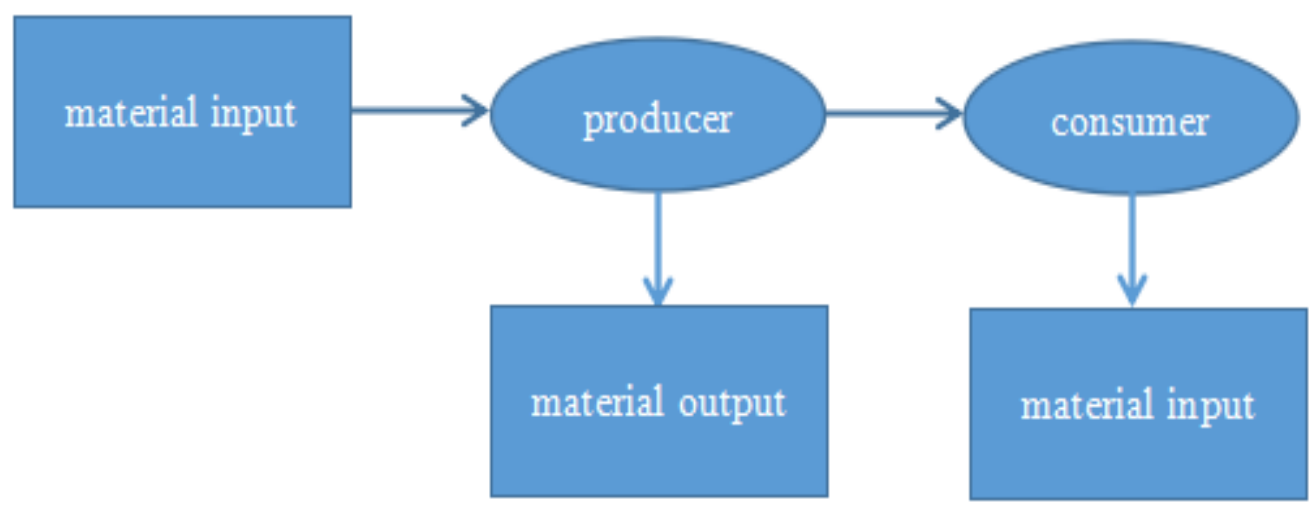

Fig.2 The running mode of current social economy

The ideal socio-economic ecosystem should be a semi-open system with only energy exchange with the outside world. In this system, decomposers match producers and consumers to perform the functions of material circulation, energy flow and information exchange (see figure 3). This model is the ideal form of circular economy operation mode. In this ideal form, we can also achieve the corresponding goal of low-carbon economy. In the real economy, which kind of material and energy is used depends on the actual market price of each kind of material, energy and its service. Market value is the actual driving force of material flow and energy flow in human economic society. Therefore, in order to change from the current unsustainable operation mode to the circular economy operation mode and ensure that the circular economy operation mode can be realized under the current market economy conditions, it is necessary to adopt various policy tools or technological innovations. The price of the material input produced by the decomposer in the system is not higher than the price directly input from the natural material outside the system, in this way, the regenerative substances produced by decomposers are more cost effective than the raw materials input outside the system, and the regenerated substances produced by decomposers can fully enter the process of reproduction, so that the material circulation can be effectively realized economically.

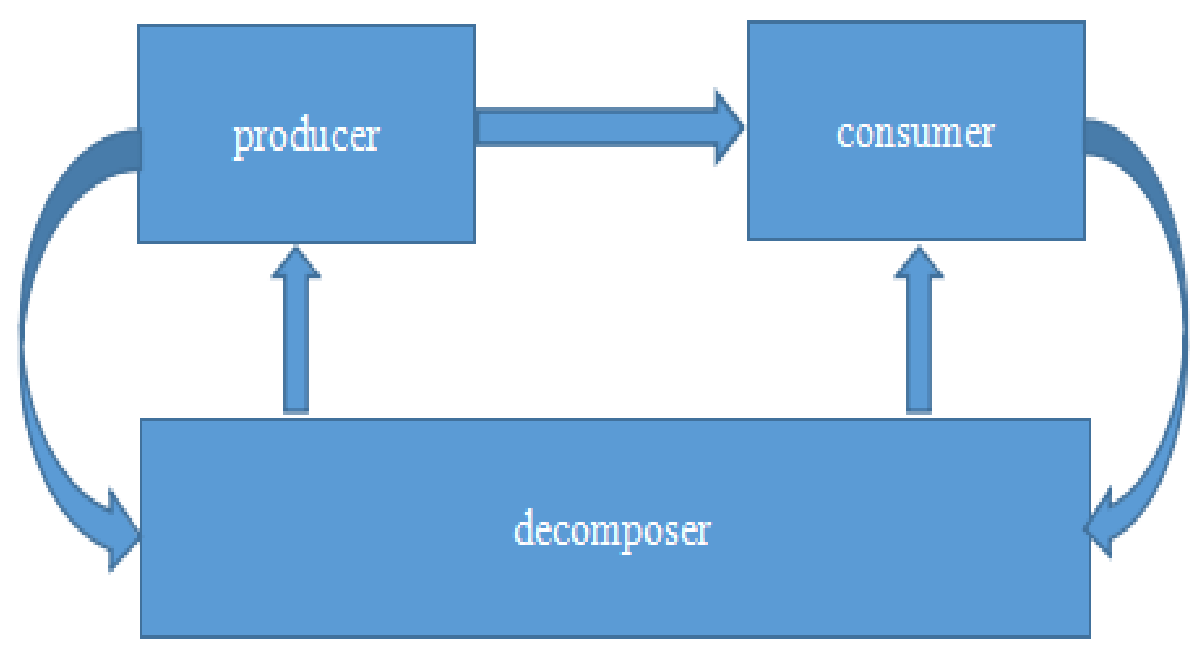

Fig.3 The operating mode of circular economy

\section{The Trend of Harmonious Development of Low Carbon Economy and Circular Economy}

Recycling economy is to rely on the recycling of resources to reduce the use of new resources as much as possible, to reduce the amount of waste emissions as much as possible, and to solve the 
environmental protection and sustainable development problems. In essence, low-carbon economy is a new revolution in economic development, energy consumption and human life style. It is a comprehensive transformation of modern industrial civilization based on fossil fuels (energy). It is urgent to solve the environmental problems and ecological problems. Although the development of circular economy in our country is not perfect, the use of circular economy has been synchronized with that of the world.

For our future planning, the government has also made clear guidance, the future development direction is mainly to build a resource-saving friendly society, so as to promote the harmonious coexistence of society and environment. We must do the following: first, to cope with energy depletion, to develop new sources of energy. Because of the wanton exploitation of mankind, fossil energy is on the verge of gradual depletion. Science and technology innovation, the development of new types of energy are important means to deal with energy depletion and protect energy effectively.

Second, we should do everything possible to make the resources be used effectively. The protection of coal resources in China is not enough, which has affected the pace of China's economic development. There is a serious phenomenon of single resources and low reuse efficiency, so we urgently need to increase the development and utilization of coal mine energy technology, to develop alternative resources, to do everything possible to make the resources to be used effectively. Third, to select a scientific and reasonable economic development model. At present, there are many pressures on China's ecological environment: thousands of drought areas, high cold and anoxic areas, large proportion of the dissolving areas, serious soil and water losses, and large population. The average share of resources is low and the utilization rate of resources is low, which seriously affects the future of China's development. Therefore, selecting a scientific and reasonable economic development model, optimizing the environment and developing the economy scientifically and rationally are the primary goal for China's development.

\section{Countermeasures for Coordinated Development of Circular Economy and Low Carbon Economy}

\subsection{To formulate a national strategy for the coordinated development of circular economy and low-carbon economy}

Circular development and low-carbon development are the inherent requirements of the construction of ecological civilization and are important strategies and technical means to realize the sustainable development of Chinese economy. The coordinated development should be established as the mode of economic development for China's economic transformation to cope with climate change. Following the path of sustainable development with Chinese characteristics is conducive to enhancing comprehensive competitiveness, scientific development and the realization of our development goals. Adhering to the basic national policy of saving resources and protecting the environment as soon as possible, taking the construction of a resource-conserving and environment-friendly society as a carrier, and the study and formulation of a coordinated development strategy between the national circular economy and the low-carbon economy, to strengthen the resource output rate and carbon emission intensity of social and economic development, guide and lead the government, enterprises and residents in the direction of action and behavior.

Specifically, the strategic orientation of a low-carbon road with Chinese characteristics should include the following aspects: First, under the framework of sustainable development, the concept of recycling and low-carbon development should be taken as the key content to build a resourceefficient, environment-friendly society and an innovative country, and the government should incorporate them into the concrete practice of sustainable industrialization and sustainable urbanization, and integrate the relevant objectives into various plans and policies. Second, it is necessary to balance the short-term and long-term objectives of economic development and climate protection, adopt a gradual path that conforms to both national conditions and world development 
trends, and properly handle the relationship between leapfrogging the heavy chemical industry stage and low-carbon transformation by taking advantage of strategic opportunities. At the same time, the synergistic effects of carbon emission reduction, energy security and environmental protection should be fully considered to effectively reduce the cost of emission reduction. Three, we should strengthen the coordination and cooperation between the departments and regions, attract the wide participation of all stakeholders and give full play to the enthusiasm of all aspects of society. Through new modes of international cooperation and institutional innovation, we will work together to promote the transformation of production patterns, consumption patterns and global resource asset allocation patterns. Fourth, to take an active part in the negotiations on the international climate regime and the formulation of low-carbon rules, to strive for greater development space for China's industrialization process.

\subsection{To actively develop relevant scientific research technologies}

In order to solve the problem of excessive dependence on fossil energy in our country, we need to form an effective cycle model, that is, a low-carbon emission system with diversified functions, which is also to alleviate the energy shortage problem now. Therefore, the future development of carbon cycle economy should be combined with the future energy environment. Now, the most promising future energy is renewable energy (solar, wind, hydro, etc.) and if we want to make better use of these "wealth" of nature, we need more advanced technology to acquire them. This makes it "urgent" for us to develop new ecological technologies. Only if the technical support is strong enough, can we further say how to make more use of renewable energy. The use of renewable energy can not only protect the environment, but also guarantee the energy security of the country, which is undoubtedly important for the development of a country. Therefore, it is more necessary to encourage the corresponding enterprises to the active research and development of ecological technology. Now, by analyzing the problems in the energy industry of our country, we can find that there are still some defects in this respect. The professional technology is backward with the world level, and the corresponding development technology and equipment become one of the backward factors. Therefore, how to build a new circular economy system has become the most important problem we need to solve. Ecological technologies mainly include cleaner production technology, renewable energy technology, recycling of water resources and so on. All of these are aimed at energy saving and climate change. In the development of new energy, we should pay attention to the adjustment of energy structure, to ensure that the energy structure is corresponding to the corresponding promotion method, which is enough to reduce the cost of funds and ensure the overall efficiency of the energy system to maximize.

\subsection{To implement universal low-carbon activities through social impact}

The formation of a perfect low-carbon circular economy system requires not only the advanced technical means, but also the corresponding economic environment, legal norms and so on. With the improvement of national economy level, they also have a new definition of social values. In order to ensure the sustainable development of low-carbon activities in the final cycle economy, the active participation of the public is needed, so that the development direction of the carbon cycle can be strengthened with the help of the collective strength of the people. For people to participate actively in the proposal, the focus is on how to motivate them correctly, and how to guide them to become one of the most important issues. This requires the government and the corresponding enterprises, companies, investment associations, scientific research institutions and other multiparty cooperation, through effective publicity, to achieve the ultimate goal of ecological education to promote the idea of green environmental protection.

Firstly, the industrial structure and energy structure should be adjusted rapidly by combining the factors of harmonious development of circular economy and low carbon economy. Second, to improve the economic laws and regulations to ensure the healthy operation of the market economy. Third, to establish market-oriented resource allocation model. Finally, to actively develop circular economy and low-carbon economy harmonious development in the pilot area. The pilot areas for the harmonious development of circular economy and low-carbon economy refer: Based on the 
concept of harmonious development of two kinds of economy, to guide the urban traffic, construction and community activities to carry out the development direction of low carbonization of circular economy, so that the city can realize green production and green consumption. Take Wuhan as an example, considering the residents' clothing, food, housing and transportation. In the residential buildings of the city, it should select the good lighting position, in order to effectively introduce a new type of energy-the use of solar energy, and develop and use new energy vehicles and other vehicles. It can effectively reduce the pollution of automobile exhaust to the environment, promote the introduction of green plant planting technology, guide the concept of green consumption of residents, and cultivate the idea of saving water and energy. In order to develop and popularize the concept and technology of low carbonization of circular economy, we should organize green and environmental protection activities on campus.

\section{Summary}

The idea of developing low carbonization in circular economy can break through the predicament when promoting circular economy or low carbon economy, realize the mutual benefit between circular economy and low carbon economy, and show the wisdom of human beings to deal with the contradiction between economic and social development and resources and environment. It is the ecological philosophy view of sustainable development, with foresight and strategy. At present, not every enterprise and consumer as the executive body can understand its scientific idea, and the cooperation between people, social groups and social groups, countries and countries remains to be done. At the same time, drawing lessons from foreign experience, economic development depends on the market and environmental supervision relies on the government. We should actively develop and apply ecological technologies, establish a policy system corresponding to the new development model, and encourage the participation of the whole people, in order to find a path of resource saving and environment-friendly development with Chinese characteristics.

\section{References}

[1] Huang Xianwei, Li Xi. Analysis on the factors influencing the harmonious Development of low carbon economy and Circular economy [J]. Modern Economic Information, 2017, (21): 3-4.

[2] Liu Shuang, Miao Chengli. Thoughts on the harmonious Development of low carbon economy and Circular economy[J]. Industry and Science and Technology Forum, 2017, (11): 18-19.

[3] Bao Wen. Study on the overall development of low carbon economy and circular economy taking Sichuan as an example[J]. Technical economy and Management Researc, 2011, (04): 86-89.

[4] Yang Yunxing. Analysis of ecological economy, circular economy, green economy and lowcarbon economy[J]. Forward Position, 2011, (08): 94-97.

[5] Bao Wen. Compared with the development model of low carbon economy and circular economy[J]. Business Age, 2011, (02): 11-12.

[6] He YF, Zhu Bin, Hong Liyun, Zhou Wen Halber.Analysis of the relationship between Circular economy and Low-Carbon economy based on Resource Productivity[J]. Technical Economy, 2010, (12): 68-73.

[7] Han Baohua, Li Guan. Similarities and differences between low-carbon economy and circular economy and their integration[J]. Jiangnan Forum, 2010, (10): 4-6. 